\title{
Pharmacy staff views on the implementation of patient handheld medication tools to improve information transfer: a qualitative study
}

Tasneem Waly ${ }^{1,2}$, Sara Garfield ${ }^{1,2^{*}}$ and Bryony Dean Franklin ${ }^{1,2}$

\begin{abstract}
Background: The risks of poor information transfer across healthcare settings are well documented, particularly for medication. Various patient-held tools have been designed to hold information about patients' medicines to improve information transfer. Anecdotal evidence suggests some are more widely implemented than others, but there has been little research exploring the reasons why. Our objectives were to explore the facilitators and barriers to implementation of patient handheld medication information from the perspective of pharmacy staff, to understand why some tools are more widely implemented than others and to make recommendations as appropriate.
\end{abstract}

Method: Semi-structured interviews were conducted with 15 pharmacists and pharmacy technicians working in wards and/or dispensary of a London hospital organisation. Participants were recruited using convenience sampling. We asked about six purposefully selected tools designed to be carried by patients to provide information about their medicines, including both national and local tools, and those that were new and established. Interviews were audio-recorded and transcribed verbatim. We used framework analysis, based on a theory of behavioural change.

Results: The majority of participants expressed the view that older tools, such as the steroid card and warfarin booklet, were used more often than newer tools such as a medication passport and a specific insulin passport. Interview data suggested that pharmacy staff did not have enough information and training about the proper use of the newer tools and therefore lacked confidence in providing them to their patients. In addition, they perceived that they were not integrated into policies and procedures with a lack of guidance regarding their use.

Conclusion: We identified the main barriers to effective implementation of tools to increase patient safety across healthcare settings to be lack of guidance and training for newer tools. Making a tool available is not sufficient to ensure its use. Recommendations include clarifying guidance within the hospital organisation to standardise use of all tools and raising awareness and providing training to both healthcare professionals and patients about their use.

Keywords: Medication cards, Medication passports, Medication information, Facilitators, Barriers, Implementation

\footnotetext{
* Correspondence: sara.garfield@nhs.net

${ }^{1}$ Research Department of Practice and Policy, UCL School of Pharmacy, London, UK

${ }^{2}$ Centre for Medication Safety and Service Quality, Pharmacy Department,

Imperial College Healthcare NHS Trust, London, UK
}

(c) The Author(s). 2018 Open Access This article is distributed under the terms of the Creative Commons Attribution 4.0 International License (http://creativecommons.org/licenses/by/4.0/), which permits unrestricted use, distribution, and reproduction in any medium, provided you give appropriate credit to the original author(s) and the source, provide a link to the Creative Commons license, and indicate if changes were made. The Creative Commons Public Domain Dedication waiver (http://creativecommons.org/publicdomain/zero/1.0/) applies to the data made available in this article, unless otherwise stated. 


\section{Background}

The risks of poor information transfer across health care settings are well documented, particularly for medications [1]. It has been estimated that up to $60 \%$ of patients admitted to hospitals have at least one discrepancy on their admission drug history [2]. While there are relatively few UK studies, in March 2007, the National Reporting and Learning System for England and Wales reported 7070 medication errors involving admission and discharge, including two fatalities and 30 cases of severe harm [3]. Empirical studies suggest that in the hospital setting, prescribing errors are most likely to occur at the time of admission, largely due to challenges of medication reconciliation [4, 5]. An audit of more than 8600 patients across 50 acute hospital trusts found that when medicines were checked after admission, most patients had at least one drug omitted or prescribed with the wrong dose [6]. Earlier estimates suggested that 30 to $70 \%$ of patients have either an error or an unintentional change to their medicines when admitted to hospital [3]. Problems are also common following transfer from hospital into the community $[7,8]$ and when attending outpatient appointments [9]. A survey completed by 1133 London general practitioners to identify priorities for improvement of medication safety in primary care identified incomplete reconciliation of medication as the highest priority [9].

Increasing patient and carer involvement with their medication records is a potential approach to improving information transfer across settings. Several paper-based documents are available for use in the UK to be carried by patients to provide information about their medicines. One is "My Medication Passport" (MMP) [10], used to record details of the patient's medications. Others are used for specific medications such as insulin, corticosteroids, warfarin and other anticoagulants. Such tools are often supplied by pharmacy staff with the dispensed medicine and are intended to help patients and carers to communicate details of their medication to other healthcare professionals as well as providing important information for the patients themselves.

Previous studies suggest that many patients bring some information about their medicines to hospital, although this is rarely a formal document $[1,10,11]$. However, research in this area is limited. Two previous studies have focused on MMP $[10,11]$ and another documented the information that patients brought into hospital [1] without exploring its use in more detail. While the two studies on MMP yielded some information on its use, they were limited to a case study [11] and telephone interviews [10] to find out whether patients had used their passport, with whom they had shared it and their suggestions for improvement.
Local anecdotal evidence suggests that some tools are more widely implemented than others. Most of the available literature on handheld medication information tools was based on the patient's point of view $[10,11]$. The aim of this study was to explore the facilitators and barriers to the implementation of patient handheld medication information tools from the perspective of pharmacy staff. We sought to understand why are some may be more widely implemented than others and to make recommendations to improve their implementation and enhance patient safety. Pharmacy staff were chosen as they supply most of the handheld medication information tools as part of the medication safety program.

\section{Methods}

Study design

Semi-structured interviews with pharmacy staff (see Appendix for interview guide).

\section{Setting}

The study was carried out at a hospital organisation in London with three main sites. Pharmacy staff in the organisation provided a range of clinical services including medicines reconciliation, medication review, attendance on some ward rounds, checking discharge prescriptions for appropriateness and carrying out patient consultations in some outpatient clinics. Inpatient and discharge medication was supplied by the pharmacy department, which also provided a medicines information service.

\section{Tools}

We evaluated six different handheld medication information tools (Table 1): (1) MMP [10], (2) the insulin passport [12], (3) the warfarin 'yellow booklet' [13], (4) alert cards for direct oral anticoagulants [14, 15], (5) the steroid card [16] and (6) a locally produced medicines helpline card given out with discharge medication [17]. These were chosen purposively to include both local (medicines helpline card) and national tools (the insulin passport [12], the warfarin 'yellow booklet' [13], anticoagulant alert cards [14, 15], the steroid card [16] and the MMP [10]) and to include those that had been recently implemented (insulin passport introduced in 2012 and MMP and anticoagulant alert cards in 2013) and those that had been in place for some time (steroid card and medicines helpline card in use since the mid-1990s, yellow warfarin booklet in place at least 25 years). All tools are available free of charge at the point of use.

\section{Sampling strategy}

The researchers aimed to interview 15-20 pharmacists and pharmacy technicians working on wards and/or in the dispensary. The pharmacists were recruited based on 
Table 1 Description of tools

\begin{tabular}{llll}
\hline Tool & Description & Year implemented & Local or national \\
\hline MMP & $\begin{array}{l}\text { Allows documentation of personal details of the patient as well as their } \\
\text { past and current medication. }\end{array}$ & 2013 & National \\
Insulin passport & $\begin{array}{l}\text { Allows documentation of personal details of the patient as well as the } \\
\text { type and dose of insulin. }\end{array}$ & 2012 & National \\
Warfarin yellow booklet & $\begin{array}{l}\text { Allows documentation of personal details of the patient as well as their } \\
\text { daily dosage of warfarin. }\end{array}$ & Almost 25 years ago. & National \\
Alert card & $\begin{array}{l}\text { Allows documentation of personal details of the patient as well as } \\
\text { information on the use of anticoagulant medication and warning signs. }\end{array}$ & 2013 & National \\
Steroid card & $\begin{array}{l}\text { Allows documentation of personal details of the patient as well as details } \\
\text { of their corticosteroid treatment. }\end{array}$ & Mid-1990s & National \\
Medicine helpline card & Provides the medicines helpline number for medicines information. & Local & Los
\end{tabular}

purposive sampling to include different genders and grades of staff.

\section{Recruitment}

The researcher recruited pharmacists and pharmacy technicians through attending clinical pharmacy meetings held weekly at the three hospitals. Pharmacists and pharmacy technicians identified as potential participants were then contacted, either by e-mail or in person, to arrange an interview. The recruited participants were not previously known to the researcher. They were informed that the researcher was carrying out the project as part of a master's degree.

\section{Data collection process}

Data collection took place between 24 May and 17 June 2016. Potential participants were given an information leaflet and invited to give informed consent. Semi-structured interviews were conducted face-to-face, audio-recorded and transcribed verbatim. TW, a pharmacy student placed at this hospital trust to complete clinical training and research as part of her master's degree, conducted the interviews. Each participant was interviewed once, and no one else was present besides the researcher and the interviewer.

\section{Topic guide}

The topic guide was developed by the researchers and piloted prior to the study. During the interviews, participants were first asked about each tool separately. They were asked to describe both the facilitators and the barriers to their implementation and what might prompt them, or prevent them, from giving them to patients. They were also asked about what healthcare professionals could do to improve their implementation and why they perceived that some were implemented more than others (see Appendix for interview guide). The transcripts were not returned to participants for comments, correction or feedback on the findings.

\section{Data analysis}

Interview data were categorised and coded using framework analysis, for which we selected Michie et al.'s [18] behavioural change framework to explore the process of behaviour change as applied to implementation. The framework comprises 12 domains: (1) beliefs about capabilities; (2) knowledge; (3) emotion; (4) environmental context and resources; (5) skills; (6) nature of the behaviour; (7) social professional role; (8) social influence; (9) behavioural regulation; (10) beliefs about consequences; (11) memory, attention and decision processes; and (12) motivation and goals. All transcribed data were entered into QRS NVivo computer software [QSR International, Victoria, Australia, version 11], which enabled organisation, indexing, sorting and retrieval of the data. The interview data were viewed and analysed by two researchers who agreed on the final themes identified.

\section{Ethical considerations}

The study was approved as a service evaluation at the hospital organisation.

\section{Results}

Thirteen pharmacists and two pharmacy technicians agreed to take part, most of whom $(n=12)$ were female. All except one pharmacist worked full time. Participants' characteristics are summarised in Table 2. Although a purposive sample was sought, the final sample was influenced by convenience, to some extent, as it depended who was available and willing to take part. The duration of interviews ranged from 15 to $40 \mathrm{~min}$, with a mean duration of $27 \mathrm{~min}$.

\section{Extent of implementation}

The majority of participants perceived that the steroid card, warfarin yellow booklet, anticoagulant alert cards and medication helpline card were widely implemented.

"I think they're implemented very well. I've seen about $100 \%$ of all patients on anticoagulants having either an alert card or an anticoagulation yellow book. Every 
Table 2 Description of participants

\begin{tabular}{lllll}
\hline Role & Site & Male & Female & Total \\
\hline Independent prescriber & Hospital 1 & 1 & 1 \\
Nephrology ward pharmacists & Hospital 1 & 1 & 1 \\
Emergency and elderly medicines1 & Hospital 2 & 1 & 1 \\
Rotational Pharmacists & Hospital 2 & 3 & 3 \\
Pharmacy technician 1 & Hospital 2 & 1 & & 1 \\
Discharge pharmacist & Hospital 2 & 2 & 2 \\
Pharmacy technician 2 & Hospital 3 & 1 & & 1 \\
Part time rotational pharmacist & Hospital 3 & 1 & 1 \\
Acute admission ward pharmacist & Hospital 3 & 1 & 1 \\
Emergency and elderly medicines 2 & Hospital 3 & 1 & 1 \\
Rotational pharmacists 4 & Hospital 3 & 1 & 1 \\
Major trauma ward & Hospital 3 & 1 & & 1 \\
\hline
\end{tabular}

single patient who's on warfarin is counselled very well here and every single patient is given a yellow book. Similarly, for the alert cards." (Acute admissions ward pharmacist)

"The steroid card and the medicines helpline card are used to $100 \%$ and are fully implemented."

(Nephrology ward pharmacist)

In contrast, the vast majority of participants were of the view that MMP and the insulin passport were not widely implemented:

"My Medication Passport! So, I don't see it a lot. I have rarely seen it with returning patients." (Pharmacy technician 2)

"I think maybe once in my life I have seen a patient with an insulin passport, if even that, so I don't think it's very widely implemented." (Major trauma ward pharmacist)

Factors affecting implementation: using Michie et al.'s behavioural change framework

Table 3 illustrates the mapping of codes to the 12 psychological domains, each of which are next presented in turn:

\section{Beliefs about capabilities}

Pharmacist's capabilities (self-confidence/professional confidence) Some participants were of the view that they did not have enough confidence to provide MMP and the insulin passport.

"So, for instance, the Insulin Passport and the Medication Passport, because they are not really part of any procedures and because, in the grand scheme of it, they are relatively new, I think people are still not very confident or they are not - it's not at the forefront of their mind to use them or to promote them. So they are not used as much, from my own personal experience." (Pharmacy technician 2)

Pharmacists' perceptions of patients' capabilities (How capable are they of maintaining/how difficult is it for them to do it?): It became apparent from the analysis that the anticoagulant alert cards, steroid alert cards, warfarin yellow books and steroid cards were seen as needing less involvement from patients than the medication passport and insulin passport. For the former tools, patients needed to understand that they have to carry them around. However, for the latter, patients needed to have more input in terms of filling them in and keeping them up to date, and interview data suggested that both perceived high and low patient capability could be a barrier. Patients perceived to have good ability to manage their medicines were not perceived to need additional tools, and patients with low ability to manage their own medicines were viewed as being unable to use the tools provided. There were therefore only a small number of patients for whom these tools were perceived to be helpful.

"For patients that are longstanding on diabetic medication I probably would assume they don't require one." (Rotational pharmacist 1 )

"Sometimes these patients forget to take their medicines, never mind write them all down very accurately on this card alongside other... There's about 50 fields of information that need to be filled out here. So, you know, I don't see it too widely used." (Major trauma ward pharmacist)

In addition, participants were of the view that the MMP and insulin passport were useful only for patients managing their own medication, not those who were having their medicines managed by carers. It was also noted that many of the tools were only available in English and therefore could not be used by those proficient in this language.

Knowledge: (knowledge about the tool/procedural knowledge) Interview data suggested that pharmacists had differential knowledge of the different tools.

Some pharmacists reported that they did not know the procedure as to whom they should supply with an MMP and at what stage they should supply it.

"I personally wouldn't really know when to give it [My Medication Passport] out or at what stage, or whether it's given out already, whether it's something I should 
Table 3 Matching between domains and codes

\begin{tabular}{|c|c|c|}
\hline Domains & Sub-domain (for some of the domains) & Codes \\
\hline \multirow[t]{3}{*}{ 1. Beliefs about capabilities } & Pharmacists' capabilities & Self-efficacy of the pharmacists \\
\hline & \multirow[t]{2}{*}{ Pharmacists perception of patients' capabilities } & Ability to manage their own medicine \\
\hline & & Having a carer \\
\hline 2. Knowledge & $\begin{array}{l}\text { Pharmacists' knowledge about the tools and the } \\
\text { procedure }\end{array}$ & Level of knowledge \\
\hline \multirow[t]{2}{*}{ 3. Emotion } & & Pharmacists' feelings \\
\hline & & Patients' feelings \\
\hline \multirow{4}{*}{$\begin{array}{l}\text { 4. Environmental context and resources } \\
\text { (environmental constraints) }\end{array}$} & \multirow[t]{2}{*}{ Factors related to the tools } & Availability of handheld medication records \\
\hline & & Design of handheld medication records \\
\hline & \multirow[t]{2}{*}{ Factors relating to the hospital environment } & Relocation of patients \\
\hline & & Time limitations \\
\hline 5. Skills & Pharmacists' skills & Level of pharmacist skill required \\
\hline 6. Nature of the behaviour & Pharmacists' behaviour towards the tools & Standard operating procedures \\
\hline \multirow[t]{2}{*}{ 7. Social, professional role } & \multirow[t]{2}{*}{ Pharmacists beliefs about responsibility } & Pharmacists' role \\
\hline & & $\begin{array}{l}\text { Other healthcare professionals' } \\
\text { responsibility }\end{array}$ \\
\hline \multirow[t]{4}{*}{ 8. Social influence (norms) } & \multirow[t]{4}{*}{ Importance of patients feedback } & Patients' feedback \\
\hline & & Pharmacy feedback \\
\hline & & Interprofessional communication \\
\hline & & Establishment of practice \\
\hline \multirow[t]{3}{*}{ 9. Behavioural regulation } & \multirow{3}{*}{$\begin{array}{l}\text { Methods needed to encourage pharmacist to effective } \\
\text { implementation }\end{array}$} & Advertisement \\
\hline & & Audits \\
\hline & & Training \\
\hline \multirow{2}{*}{$\begin{array}{l}\text { 10. Beliefs about consequences (anticipated } \\
\text { outcomes attitude) }\end{array}$} & \multirow[t]{2}{*}{ Beliefs about risks } & High-risk drugs. \\
\hline & & Polypharmacy \\
\hline $\begin{array}{l}\text { 11. Memory, attention and decision } \\
\text { process }\end{array}$ & $\begin{array}{l}\text { Factors affecting the pharmacists' and pharmacy technicians } \\
\text { attention and decision making }\end{array}$ & Forgetfulness \\
\hline 12. Motivation and goals (intention) & Methods to motivate pharmacists & Pay pharmacists to provide it \\
\hline
\end{tabular}

The 12 domains are from Michie et al. behavioural change framework [18] and the sub-domains were identified from our data

ask the patient for when they come back in, or whether it's given at discharge." (Part-time rotational pharmacist)

In contrast, participants reported that they had good knowledge of other tools such as the steroid card and yellow booklet.

"[The steroid card] is the type of thing that you are taught about when you first learn what steroids are."

(Rotational pharmacist 1)

\section{Emotion: (how does emotion affect implementation?)}

Participants rarely raised emotions as being a factor affecting implementation of handheld medication information. However, one participant described pharmacy 'passion' as an emotion that would facilitate implementation and another was of the opinion that patients' frustration would be a barrier.

\section{Environmental context and resources: (to what extent do physical or resource factors facilitate or hinder?)}

Many of the barriers identified feed into this category; these have been grouped into availability of tools, their design, transfer of patients between wards and time restrictions.

Availability of tools Respondents indicated that some of tools were more easily available in the dispensary than others. The steroid card, warfarin yellow booklet and medicines helpline or information card were reported as being readily available, whereas MMP and insulin passports were sometimes in low supply.

"The medicines information card is always used, we see it all the time in the dispensary, there's big piles of 
them in dispensary and we always give them out. Same with the steroid cards as well, that's something that we always give out. Warfarin as well, that's something that we always give out as well." (Pharmacist technician 2)

"A big barrier initially was that we just didn't have any. So we kept being told about the insulin passport but then we couldn't actually get them from anywhere. It seemed to take a long time to actually have any stock or reliable stock." (Independent prescriber)

Even for those tools where the supply was plentiful, participants reported that their availability on wards was lower, resulting in their being unable to issue them while they were with a patient unless they had brought a supply with them. The unavailability of medicines helpline cards on the wards also acted as a barrier to other healthcare professionals issuing them. This was of particular relevance where discharge medication was given from prepacks stored on the wards rather than being assembled in the pharmacy.

"Just having them available on the ward maybe. So nurses could added it into their bags if its not there. Because again we sometimes assemble the TTAs [to take away medication] on the wards. So, it's not always coming from the pharmacy. when the nurses are assembling it, they could simply add it." (Rotational pharmacist 2)

Design of tools Participants identified design problems with some of the tools: the MMP was reported to be too bulky and to not have a user-friendly design and layout as it was not pocket-sized. The trifold nature of the insulin passport was also reported to be unmanageable. The medicines helpline card was reported to be so small that it could be lost and the steroid card to be outdated. In contrast, the warfarin yellow booklet was perceived to be well designed. In general, pocket-sized medication information was considered preferable.

"I think particularly for male patients who don't always carry a bag, you know, it's not so easy to put some of these in your pocket, they're not of insubstantial size." (Independent prescribing pharmacist)

Patient transfer Participants indicated that providing patients with tools was challenging when patients were transferred to other wards, as the pharmacist would be unable to go and find them before they were discharged.
"By the time I get round to it, they've moved off, so they're not on my ward any more, they're not within my service to be able to...I can't go and find them, they might have moved to a medical ward, they might have gone home already." (Emergency and elderly medicine ward pharmacist 1).

Time limitations The vast majority of participants identified time as a barrier. While this was the case for all the tools, this was most frequently raised as a barrier for the insulin passport and MMP. These two tools were thought to need a lot of education from the pharmacy staff to the patient for effective implementation.

"Especially, I've found, with the Medication Passport. Unless you explain how it works, there's no point in giving it to someone. So I think they have the potential to be really, really beneficial, but along with just giving it to a patient, you have to have that education to go with it. That's just the part that's more time-consuming and just needs a bit more work on, I think." (Acute admission ward pharmacist).

\section{Skills}

Skill level was rarely raised by participants as a factor affecting implementation. However, one participant expressed the view that the steroid card was a much simpler tool to implement than MMP and could be actioned by a relatively inexperienced member of staff.

"It's a very simple sort of a card I suppose as well; it doesn't require a lot of input. In fact, some of the only input it requires is for someone to stick a label on it; the label can easily be issued twice by just changing the, sort of, profiles of drug and [pharmacy dispensing system]. You ask [pharmacy dispensing system] to issue two new labels, that's the other prompt with a dispenser who could be a Band 2 [pharmacy assistant with little formal training] for all we know, that this medicine requires a steroid card." (Major trauma ward pharmacist)

\section{Nature of the behaviour: (routine/automatic/habit)}

Participants expressed the view that tools would be more widely implemented if they were integrated into standard operating procedures (SOPs). The yellow warfarin booklet, steroid cards and the medicines helpline card were all described as being incorporated into hospital procedures. Some participants were also of the view that the insulin passport and new anticoagulant alert cards were embedded into SOPs, whereas others were not. No 
participants expressed the view that the MMP was part of SOPs and some participants specifically stated that it was not.

"Well some are ingrained into us through standard operating procedures. And others are more... So for example the steroid, the helpline, that's all ingrained into us in SOPs. However, the medication passport is more if you think the patient needs it then it's at the discretion of either their ward based technician or the pharmacist once they've spoken to the patient." (Nephrology ward pharmacist)

\section{Social, professional role}

Interview data suggested that some tools were seen as a core part of a pharmacist's role, whereas others were seen as 'medicines management' and something that could be taken on by other healthcare professionals. For example, the variable dosing of warfarin dependent on the international normalised ratio meant that the warfarin yellow booklet provided information about the dosage, which would not be on the medication label and this was therefore seen as an essential clinical process. Likewise, steroid alert cards were seen as essential as the requirement to issue these is specified in the BNF [British National Formulary]. However, the MMP and insulin passport were seen as medication management tools. Participants were of the view that issuing the MMP was seen as a pharmacy role, but this should not necessarily be the case. Some participants discussed the specialised diabetes nurse as the person who had the role of providing the insulin passport.

"So all of our anti-coagulation...it's the job of the pharmacist to make sure they get it, and because that's part of our role and our safety role, I think the implementation of those are probably one of the best, and then as you go down, you have to seek patients to implement My Medication Passport currently, it's not offered to everyone." (Emergency and elderly ward pharmacist 1)

"There is a feeling that it's (the steroid card) a clinical issue. I think sometimes in pharmacy there are things that are medicine management issues that are treated differently to things that are considered clinical issues. Medicines management are ... sometimes I think goes by the wayside." (Pharmacy technician 1)

"Maybe involving the nurses a bit more into the different passports that we have and then they can identify patients that are suitable as well as us. And hand them out as they see fit. It doesn't have to just be pharmacists. It's not really a clinical intervention.
It's just information for the patient." (Rotational pharmacist 1)

\section{Social influence: (team working/feedback)}

Some participants reported that they were interested in getting feedback from patients who were issued with the MMP, the insulin passport or the steroid card. Another participant was of the opinion that healthcare professionals should have the opportunity to feed back about the handheld tools. It became apparent from the analysis that inter-professional communication was also an issue in terms of handovers and ensuring that all healthcare professionals knew when a member of pharmacy staff had identified that a patient would benefit from a given tool.

Behavioural regulation: (are there procedures or ways of working that would encourage implementation?)

Findings in this area relate to raising awareness, audits and training.

Awareness raising Participants were of the view that raising awareness of some of the handheld medication information, especially the newer ones such as the MMP and the insulin passport, might encourage wider implementation. Advertisements could be to pharmacy staff, other healthcare professionals or directly to patients. One participant thought that patients could be used a direct mode of advertising to others.

"Teaching sessions, posters, just like highlighting medication passports. I think in my old trust we had a poster for nurses so they were aware of it so sometimes you'd get a phone call from one of them being like, 'We need one'." (Discharge pharmacist)

Audits Two participants believed that organising regular audits on the use of the handheld medication information might encourage more healthcare professionals to provide them to their patients.

"Regular audits to see how much use of these cards is helping patients and how much it's being used. Providing feedback on these audits so that different departments can help facilitate the use of them more. So, by giving feedback, we can develop strategies to perhaps use them more, if that makes sense." (Acute Admission ward Pharmacist)

Training Participants were of the view that training staff and patients would facilitate implementation. Participants 
differentiated between the training that was in place for the warfarin yellow booklet and steroids and that available for other tools, such as the MMP, insulin passport and medicines helpline card.

"I don't really feel that, apart from the warfarin, and also maybe the steroid cards, there's no real set way or I've never been trained in being, 'So this is a Medicines Passport, this is how we should be promoting them.' There's never been a set, 'Oh, with Medicines Passports, make sure you say this with a patient.' And that may be something useful coming from the people who are producing them. Because if they want to promote these, then they should be having a set list of things that they want us to push through as healthcare professionals." (Major Trauma ward pharmacist)

\section{Beliefs about consequences (anticipated outcomes)}

Participants were of the view that high-risk drugs or situations would prompt them to offer the tools to patients. Anticoagulants, steroids and insulin were identified as high-risk drugs. However, while this meant that the warfarin booklet, anticoagulant alert cards and steroid card were widely implemented, this was not necessarily the case for the insulin passport, suggesting that beliefs about consequences may only facilitate implementation if other factors are also present.

"They're high risk drugs. They're associated with significant harm if not taken appropriately. So I suspect that's why we issue the alert cards for steroids and warfarin, and now for insulin, because of the risks associated with it. So I suppose drugs which are associated with high risks contribute to the implementation of these things. ... The insulin passport is a newer initiative, and I think the reason why it's been introduced is because of the risks which have occurred where patients are inadvertently taking incorrect insulin. [...] Although it's important, I suppose the awareness needs to be upped a lot more in a similar way to the warfarin and the steroid booklets." (Part-time rotational pharmacist)

Similarly, two participants expressed the view that polypharmacy would be a prompting factor to offer patients an MMP.

"In particular, we need to identify those patients who have quite a few drugs and often may involve quite a few changes in their medications when they're transferred from GP to hospital." (Rotational pharmacist 3)

\section{Memory, attention and decision process}

Issues related to forgetfulness were raised as barriers to implementation of all the tools apart from the yellow warfarin booklet. However, while forgetfulness was raised for a whole range of tools, participants were of the view that the newer tools including the insulin passport, the MMP and the newer anticoagulant alert cards had not become part of a habit-forming process and were therefore less likely to be issued.

"As part of the drug history we don't routinely ask them, and that might just be habit, and we haven't developed it into a habit when we ask them about their insulin. I don't ask them about a passport."

(Rotational pharmacist 1)

\section{Motivation and goals (intention)}

Issues related to motivation and goals were rarely raised by participants. However, one pharmacist suggested that one way of encouraging pharmacists to provide the MMP was to pay them for issuing it.

\begin{abstract}
"They could probably attribute a cost to the anticipated days saved or something of a hospital duration if everyone in the NHS came into hospital with a medication passport. So if that cleared up all sorts of medication incidents that prolonged hospital admission, attribute a cost to that, then pass that cost or saving potentially on to the trust with CQUINs [Commissioning for Quality and Innovations incentives] or incentives or giving helpful pharmacists like myself $£ 5$ every time they issued one to a patient." (Major Trauma ward pharmacist).
\end{abstract}

\section{Discussion}

The steroid card, yellow warfarin booklet, anticoagulant alert cards and medicines helpline card were reported to be much more widely implemented than the insulin passport and MMP. This is in agreement with the study by Walkers and Wilcock [19] that has demonstrated poor implementation of the insulin passport, with only $4 \%$ of patients bringing a complete passport with them into hospital and only third of the total patients having actually heard of them. Findings suggest that the main reasons for these differences in implementation were that the former tools have been part of both the SOPs at the hospital organisation and pharmacy staff education and training. Participants were of the view that the high-risk medications such as the anticoagulants and the steroids facilitated distribution of some associated tools. However, this was not reported to be the case with the newer tools, even for higher risk medication (insulin). 
Participants expressed uncertainty about whether issuing an insulin passport was the pharmacist's responsibility or another healthcare professional's such as a diabetic specialist nurse. In contrast, the steroid card was perceived as a clinical process that is part of the pharmacist's role as is specified as a requirement in the BNF. The medicines helpline card and the steroid card have been implemented for more than 20 years and seem established in the pharmacy staff's dispensing role. While the medicines helpline card is recommended to be given to all discharged patients, the MMP is left to professional discretion and judgement by the pharmacist or technician, introducing an inherent lack of standardisation. The perceived low implementation of the medication passport and insulin passport is in agreement with the study by Dharas and Franklin [1], which found that only one admitted patient of 144 brought MMP into hospital during the study period [1]. However, Barber et al. [11] found that more than half of patients who had received an MMP and agreed to take part in a telephone interview had used it and found it useful. This contrasts with the view of the pharmacists in our study who perceived the MMP to be useful only in a small group of patients and that others will not use it. This may reflect the fact that either pharmacists make good judgments about who should receive the MMP or it may indicate that patients find the MMP more helpful than the pharmacy staff believe. There was strong agreement among the participants in this study that newer tools (MMP and the insulin passport) need much more input in terms of pharmacists' and patients' education than older tools such as the warfarin yellow booklet, the anticoagulant alert cards and the medicines helpline card.

\section{Strengths and limitations}

This study is the first to evaluate the implementation of patient handheld medication information using a psychological framework. In addition, six tools were compared, whereas previous studies evaluated only one tool per study. Another strength was that we were able to recruit a wide range of pharmacy staff including pharmacists and pharmacy technicians. Although we had originally planned to use purposive sampling, practical constraints meant that a convenience sample had to be used, and only two pharmacy technicians were able to participate. Other limitations are that we did not collect data about participants' age and work experience, that we were not able to triangulate our findings with quantitative implementation data and that the study was conducted at one hospital organisation. Conducting another larger study among other hospitals may provide cumulative validity and more generalisability.

\section{Recommendations}

\section{General recommendations}

Hospital organisations should formulate guidance to specify those patients who should receive which tool. This could include criteria for issuing a tool in terms of the treatment being received by the patient and other patient characteristics. It would be helpful if tools were also available in different languages. Hospital organisations may need to increase the awareness among healthcare professionals of the availability of different tools such as through posters and training sessions, in order to include them in consultations and in patient and family education.

\section{Recommendations for the specific tools}

Printing MMP in a smaller format, to fit patients' pockets, may be useful. Also, as some participants found difficulty in folding the insulin passport, changing its design into a booklet might assist pharmacy staff and/or patients to complete it. Modernising the design and layout of the steroid card might encourage patients to use it more often and raise its profile among pharmacy staff. It would be useful to have a single tool that combines the functions of two or more tools for patients on two or more high-risk medications, instead of having to carry more than one.

\section{Conclusion}

The main facilitators to the implementation of the widely implemented tools such as the warfarin yellow booklet and the steroid were that they had been integrated into SOPs and training at local and/or national level. On the other hand, the newer tools did not have these facilitators and participants reported that they were less widely implemented. Integration of patient handheld tools into SOPs may improve patient safety across healthcare settings.

\section{Appendix}

\section{Interview guide}

My name is Tasneem Waly. Thank you for agreeing to take part in this interview. I am speaking to pharmacy staff to understand what are the barriers and facilitators to the implementation of patient hand held medication cards and records from their perspective. I am interested in your thoughts and opinions; there are no right or wrong answers. With your permission I would like to record this interview. This is so that I can concentrate on what you are saying rather than writing it down. I will then type this up and remove any information that identifies you personally. If you would like to stop the recording at any point, or skip questions or take a break please let me know. I will 
ask you 10 questions, which will take approximately 20-30 minutes. Do you have any questions? Is it ok if we begin now?

To what extent do you think My Medication passport is implemented?

Prompts:

- Can you give me more details about that?

Probes:

- Could you tell me a bit more about that? Why is that?

- Can you give me an example of that?

A) What may prompt you to offer it to a patient?

B) What might prevent you from offering it to a patient?

C) What might be the general facilitators to its implementation?

D) What might be the general barriers to its implementation

1. To what extent do you think the steroid card is implemented?

Prompts:

- Can you give me more details about that?

Probes:

- Could you tell me a bit more about that? Why is that?

- Can you give me an example of that?

A) What may prompt you to offer it to a patient?

B) What might prevent you from offering it to a patient?

C) What might be the general facilitators to its implementation?

D) What might be the general barriers to its implementation?

2. To what extent do you think the insulin passport is implemented?

Prompts:

- Can you give me more details about that?

Probes:
- Could you tell me a bit more about that? Why is that?

- Can you give me an example of that?

A) What may prompt you to offer it to a patient?

B) What might prevent you from offering it to a patient?

C) What might be the general facilitators regarding its implementation?

D) What might be the general barriers to its implementation?

3. To what extent do you think the oral anticoagulant booklet and the alert cards are implemented?

Prompts:

- Can you give me more details about that?

Probes:

- Could you tell me a bit more about that? Why is that?

- Can you give me an example of that?

A) What may prompt you to offer it to a patient?

B) What might prevent you from offering it to a patient?

C) What might be the general facilitators to its implementation?

D) What might be the general barriers to its implementation?

4. To what extent do you think the medication helpline card is implemented?

Prompts:

- Can you give me more details about that?

Probes:

- Could you tell me a bit more about that? Why is that?

- Can you give me an example of that?

A) What may prompt you to offer it to a patient?

B) What might prevent you from offering it to a patient?

C) What might be the general facilitators to its implementation?

D) What might be the general barriers to its implementation? 
5. What are the differences in implementation of different patient handheld medication cards and records?

\section{Prompts:}

- Why is that?

- What other things that could have impacted their implementation?

\section{Probes:}

- Could you tell me a bit more about that? Why is that?

- Can you give me an example of that?

6. What are the challenges that are faced by pharmacists and pharmacy technicians in implementing these interventions? Prompts:

- Can you describe those challenges in details?

Probes:

- Can you give me an example of that?

7. In which type of patients are those interventions difficult to implement? Prompts:

- Can you describe those difficulties?

Probes:

- Could you tell me a bit more about that? Why is that?

- Can you give me an example of that?

8. How could implementation of these interventions be increased? Prompts:

- What types of things can healthcare professionals do to improve the implementation of those interventions

- What types of things can organizational bodies improve the implementation of these interventions?

\section{Probes:}

- Can you tell me more about that? Why is that?
- Can you give me an example of that?

\section{Is there anything about implementation barriers that we have not spoken about yet?}

Thank you for taking part in this interview. Do you have any questions you would like to ask? Is there anything you would like to explain?

\section{Abbreviations}

BNF: British National Formulary; CQUINs: Commissioning for Quality and Innovations; INR: International normalised ratio; MMP: My Medication Passport; NHS: National Health Service; NPSA : National Patient Safety Agency; SOP: Standard operating procedure; TTA : To take away medication

\section{Acknowledgement}

The authors would like to acknowledge all the participants in this study and everyone who contributed to this work.

\section{Funding}

This paper represents independent research supported by the Health Foundation and the National Institute of Health Research (NIHR) Imperial Patient Safety Translational Research Centre. The views expressed are those of the authors and not necessarily those of the NHS, the NIHR or the Department of Health and Care.

\section{Availability of data and materials}

The main key findings generated/analysed during this study are included in this published article. Any other data is available from the corresponding author on reasonable request.

\section{Authors' contributions}

TW collected the data, analysed the findings and wrote the first draft. SG supervised all parts of this study and contributed largely to the analysis and in writing and editing the manuscript. BDF supervised the research and contributed to editing the manuscript. All authors read and approved the final manuscript.

Ethics approval and consent to participate NHS Ethics committee approval was not required. The study was approved as a service evaluation at the trust and had UCL ethics approval. Written consent was obtained from all the participants.

Consent for publication

The consent form is available upon request from the corresponding author.

Competing interests

The authors declare that they have no competing interests.

\section{Publisher's Note}

Springer Nature remains neutral with regard to jurisdictional claims in published maps and institutional affiliations.

Received: 30 August 2018 Accepted: 6 November 2018

Published online: 04 December 2018

References

1. Dharas S, Dean Franklin B. What information do elective surgery and emergency medical patients bring into hospital about their medication? Int J Pharm Pract. 2014;22(Suppl 2):23-106.

2. Himmel W, Kochen $M$, Sorns U, Hummers-Pradier E. Drug changes at the interface between primary and secondary care. Int J Clin Pharmacol Ther. 2004:42:103-9.

3. National Institute for Health and Care Excellence. Technical safety solutions, medicines reconciliation. 2007. https://www.nice.org.uk/guidance/psg1.

Accessed 27 July 2017. 
4. Franklin BD, Reynolds M, Shebl NA, Burnett S, Jacklin A. Prescribing errors in hospital inpatients: a three-centre study of their prevalence, types and causes. Postgrad Med J. 2011;87:739-45.

5. Tully MP, Buchan IE. Prescribing errors during hospital inpatient care: factors influencing identification by pharmacists. Pharm World Sci. 2009;31:682e8.

6. Dodds L. Unintended discrepancies between pre-admission and admission prescriptions identified by pharmacy-led medicines reconciliation: results of a collaborative service evaluation across East and South East England. IJPP. 2010;18 Suppl 2:9.

7. Royal Pharmaceutical Society. Keeping patients safe when they transfer between care providers - getting the medicines right. 2012. http://www. wessexahsn.org.uk/img/projects/rps-transfer-of-care-final-report.pdf. Accessed 27 July 2017

8. Avery AJ, Ghaleb M, Barber N, Franklin BD, Armstrong SJ, Serumaga B, Dhillon S, Freyer A, Howard R, Talabi O, Mehta RL. The prevalence and nature of prescribing and monitoring errors in English general practice - a retrospective case note review. Br J Gen Pract. 2013;63:E54-E553.

9. Burnett S, Deelchand V, Franklin BD, Moorthy K, Vincent C. Missing Clinical Information in NHS hospital outpatient clinics: prevalence, causes and effects on patient care. BMC Health Serv Res. 2011;11:114.

10. Barber S, Thakkar K, Marvin V, Dean Franklin B, Bell D. Evaluation of My Medication Passport: a patient completed aide-memoire designed by patients, for patients, to help towards medicines optimization. BMJ. 2014;4: e005608.

11. Jubraj B, Blair M. Use of a medication passport in a disabled child seen across many case settings. BMJ Case Rep. 2015. https://doi.org/10.1136/bcr2014-208033.

12. National Patient Safety Agency.The Insulin Passport. 2012. https:// webarchive.nationalarchives.gov.uk/20171030124323/http://www.nrls.npsa. nhs.uk/resources/?entryid45=130397\& $=4$.

13. Actions that can make oral anticoagulant therapy safer: Information for patients and carers. 2007. https://webarchive.nationalarchives.gov.uk/ 20171030125133/http://www.nrls.npsa.nhs.uk/resources/?entryid45= $61777 \& q=0 \%$ C2\%ACanticoagulant\%C2\%AC.

14. BayerPharmaceuticals.PatientAlertCard.2014. http://www.antithrombose.de/ datafiles/images/downloads/Patientenausweis_engl_Ansichts_RZ.pdf. Accessed 27 July 2017.

15. BoehringerlngelheimPharmaceuticals.PatientAlertCard.2013.https://www. medicines.org.uk/emc/RMM.401.pdf. Accessed 27 July 2017.

16. British National Formulary 76. London: BMJ Group; 2018.

17. Joseph A, Franklin BD, James D. An evaluation of a hospital-based patient medicines information helpline. Pharmaceutical J. 2004;272:126-9.

18. Michie S, Johnston M, Abraham C, Lawton R, Parker D, Walker A, et al Making psychological theory useful for implementing evidence based practice: a consensus approach. Qual Saf Health Care. 2005;14:26-33.

19. Walkers J, Wilcock. Implementation of the insulin passport - apparently going nowhere? Int J Pharm Pract. 2014;22:23-106.

Ready to submit your research? Choose BMC and benefit from:

- fast, convenient online submission

- thorough peer review by experienced researchers in your field

- rapid publication on acceptance

- support for research data, including large and complex data types

- gold Open Access which fosters wider collaboration and increased citations

- maximum visibility for your research: over $100 \mathrm{M}$ website views per year

At $\mathrm{BMC}$, research is always in progress.

Learn more biomedcentral.com/submissions 